\title{
A construção de políticas públicas de saúde mental com foco no trabalhador rural*
}

\section{Cláudia Farias Pezzini ${ }^{1}$}

(18) https://orcid.org/0000-0001-7777-7887

Raimundo Nonato Cunha de França'

(D) https://orcid.org/0000-0003-4490-192X

\footnotetext{
A publicação deste artigo na Série Temática "Recursos Humanos em Saúde e Enfermagem" se insere na atividade 2.2 do Termo de Referência 2 do Plano de Trabalho do Centro Colaborador da OPAS/OMS para o Desenvolvimento da Pesquisa em Enfermagem, Brasil. Artigo extraído da dissertação de mestrado "Políticas de saúde mental com foco no trabalhador rural no Brasil: problemas e avanços", apresentada à Universidade do Estado de Mato, Tangará da Serra, MT, Brasil.

${ }^{1}$ Universidade do Estado do Mato Grosso, Tangará da Serra, MT, Brasil.
}

\begin{abstract}
Objetivo: analisar a inclusão da saúde mental do trabalhador rural na construção da agenda e implementação das principais políticas públicas de saúde do território nacional. Método: estudo de caráter transversal e interdisciplinar realiza pesquisa bibliográfica e documental, investigando o "lugar" da saúde mental do trabalhador rural na construção da Política Nacional de Saúde Mental, Política Nacional de Saúde do Trabalhador e a Política Nacional de Saúde Integral das Populações do Campo, da Floresta e Águas. Resultados: embora avanços tenham ocorrido no âmbito nacional da saúde mental e saúde do trabalhador, a inclusão do meio rural ainda é tímida e a consideração do sofrimento do trabalhador do campo é praticamente nula. Conclusão: o termo trabalhador rural é pouco citado nas principais políticas nacionais e sem conceito integrativo, sendo referenciado de forma fragmentada, descontextualizada e excludente no processo inicial da definição e construção das principais políticas públicas de saúde.
\end{abstract}

Descritores: Política Nacional de Saúde; Saúde Mental; Trabalhador Rural; Atenção Psicossocial.

\section{Como citar este artigo}

Pezzini CF, França RN. The construction of public mental health policies in Brazil with a focus on rural workers. SMAD, Rev Eletrônica Saúde Mental Álcool Drog. 2021 jul.-set.;17(3):18-26. doi: https://dx.doi.org/10.11606/issn.1806-6976.smad.2021.166121 


\title{
The construction of public mental health policies in Brazil with a focus on rural workers
}

\begin{abstract}
Objective: to analyze the inclusion of the mental health of rural workers in the construction of the agenda and implementation of the main public health policies of the national territory. Method: a cross-sectional and interdisciplinary research study that conducts bibliographic and documentary survey, investigating the "place" of rural workers' mental health in the construction of the National Mental Health Policy, the National Workers' Health Policy and the National Integral Health Policy of the Rural, Forest and Waters Populations. Results: although advances have been made in the national context of mental health and workers' health, the inclusion of the rural environment is still timid and the consideration of the rural workers' distress is practically null. Conclusion: the rural worker is little mentioned in the main national policies and without an integrative concept, being referenced in a fragmented, decontextualized and excluding manner in the initial process of definition and construction of the main public health policies.
\end{abstract}

Descriptors: National Health Policy; Mental Health; Rural Worker; Psychosocial Attention.

\section{La construcción de políticas públicas de salud mental con enfoque en el trabajador rural}

\begin{abstract}
Objetivo: analizar la inclusión de la salud mental del trabajador rural en la construcción de la agenda e implementación de las principales políticas públicas de salud del país. Método: estudio de carácter transversal e interdisciplinar realiza pesquisa bibliográfica y documental, investigando el "lugar" de la salud mental del trabajador rural en la construcción de la Política Nacional de Salud Mental, Política Nacional de Salud del Trabajador y la Política Nacional de Salud Integral de las Poblaciones del Campo, de la Floresta y Aguas. Resultados: aunque se han producido avances a nivel nacional de salud mental y salud de los trabajadores, la inclusión de las zonas rurales sigue siendo tímida y la consideración del sufrimiento de los trabajadores rurales es prácticamente nula. Conclusión: el término trabajador rural rara vez se menciona en las principales políticas nacionales y sin un concepto integrador, se hace referencia de manera fragmentada, descontextualizada y exclusiva en el proceso inicial de definición y construcción de las principales políticas públicas de salud.
\end{abstract}

Descriptores: Política Nacional de Salud; Salud Mental; Trabajador Rural; Cuidados Psicosociales. 


\section{Introdução}

O atual panorama socioeconômico tem reestruturando o sentido do trabalho e ressignificado o processo saúde-doença, atingindo com vigor a zona rural brasileira. Esse meio, até então segregado e estigmatizado, tem registrado uma nova identidade mesmo diante da sua heterogeneidade. A agricultura amplia-se para além do agronegócio e é acondicionada à indústria, sendo incorporada às demandas econômicas, tornando-se importante mundialmente. Para o trabalhador, o processo de modernização passa a ser excludente por um lado e única alternativa de cidadania por outro ${ }^{(1-2)}$.

Esse rural caracteriza-se pela multissetorialidade e diversidade cultural, acoplada aos padrões tecnológicos, econômicos e ecossistêmicos, mas sobretudo, distinto do ponto fundiário, produtivo e social com implicações políticas estruturais. São comunidades com modos de vida relacionados ao campo, floresta, agropecuária e extrativismo, como: camponeses; agricultores familiares; trabalhadores rurais assalariados e temporários que residam ou não no campo; assentados e acampados; quilombolas; extrativistas; ribeirinhos; outras comunidades tradicionais; dentre outros ${ }^{(3-4)}$.

Na perspectiva de perfilhar esse setor no Brasil, o trabalhador torna-se peça-chave e sua atividade laboral se complexifica, configurando não somente fonte de renda, como determinante de vida, saúde, inclusão e interface territorial. Nesse viés, o trabalho detém tanto efeito protetor, promotor de saúde, como também de mal-estar, sofrimento, adoecimento e morte. Tais efeitos estão correlacionados ao isolamento social, possíveis vulnerabilidades e deterioração ambiental. O que gera demandas de saúde mental que deveriam impactar diretamente as ações governamentais e as políticas públicas ${ }^{(5)}$.

O país lidera o ranking com maior prevalência de transtorno de ansiedade e 18,6 milhões de brasileiros, ou seja, 9,3\% da população apresentam esse quadro. Entre 2012 e 2016, os transtornos mentais ocuparam a terceira posição entre os motivos para afastamento do trabalho, totalizando 668.927 casos. Os episódios depressivos foram a principal causa de pagamento de auxílio-doença não relacionado a acidentes de trabalho, 30,67\%, seguido de $17,9 \%$ de transtornos ansiosos. Esses transtornos (como estresse grave e transtornos de adaptação, episódios depressivos e outros) somaram $79 \%$ dos afastamentos somente nesse período(6).

Portanto, a compreensão desse novo paradigma rural alinhado as questões de saúde e doença com foco no sofrimento mental é, sem dúvida, um desafio. Nesse sentido, essa reflexão baseia-se na necessidade de alvitrar uma investigação a partir da tríade mentaltrabalho-rural, bem como refletir sobre a inclusão dessa demanda no debate sociopolítico a fim de contribuir para a construção das políticas públicas com foco em prevenir, acolher e tratar o portador de transtorno mental que trabalha no campo(7).

O estudo pauta-se numa discussão interdisciplinar transversal a partir da investigação comparativa dos conceitos de rural e saúde mental na análise sóciohistórica das principais Políticas Nacionais de saúde: a Política Nacional de Saúde Mental, a Política Nacional de Saúde do Trabalhador e a Política Nacional de Saúde Integral das Populações do Campo, da Floresta e das Águas.

Tem como objetivo central analisar a inclusão da saúde mental do trabalhador rural na construção da agenda e implementação das principais políticas públicas de saúde do território nacional, partindo da problematização norteadora: qual o lugar da saúde mental do trabalhador rural na saúde pública com base na elaboração das Principais Políticas Nacionais de Saúde do Brasil?

\section{Método}

Esta é uma pesquisa interdisciplinar, bibliográfica de caráter transversal descritiva que tem como opção metodológica um estudo exploratório de abordagem qualitativa, com recorte temporal do período de 1990 a 2018. A escolha do período delimitado foi definida conforme a data da primeira lei coletada (Lei No 8.213, de 24 de julho de 1991) até o ano da finalização da busca de dados (2018).

Analisa de forma comparativa os temas "trabalhador rural" e "saúde mental" na construção das três Políticas Nacionais, utilizando as bases de dados SciELO (http:// www.scielo.org), Cadernos oficiais publicados pelo Ministério da Saúde (http://bvsms.saude.gov.br) e Diário Oficial da União (http://www.in.gov.br/servicos/ diario-oficial-da-uniao).

As etapas para a coleta de dados seguem: 1) Identificação geral: busca de legislação, portaria, normativa, lei referentes às políticas nacionais; 2) Triagem: delimitação dos temas e período; 3) Confirmação dos dados: em cadernos oficiais do Ministério da Saúde e Diário Oficial; 4) Elegibilidade: critérios de exclusão - legislações estaduais, não publicadas oficialmente e critério de inclusão - legislação federal; 5) Tabulação e Coleta final: pesquisa em cada item com novos descritores - na Política de Saúde Mental: "usuário" e nas outras duas: "saúde mental" e "trabalhador rural".

A escolha do campo federal pressupõe um panorama seguro norteador a fim de traduzir problemas candentes desde a sua implementação. O marco metodológico da pesquisa coaduna na investigação e correlação histórica, destacando a criação das principais diretrizes políticas. Ou 
seja, pauta-se na busca idiossincrática que regula esse tipo de pesquisa. O estudo sustenta a agenda política como principal traço, focando na identificação do tipo de problema que visa corrigir, no processo percorrido, nas arenas sociais e regras que irão modelar a decisão e a implementação das políticas públicas ${ }^{(8)}$.

\section{Resultados}

No período do estudo foram encontradas o total de 197 leis, portarias e normativas federais divididas em 3 sessões, segundo cada política. Na primeira etapa é possível conferir o número de leis e portarias com o número de vezes em que o rural é citado (Figura 1).

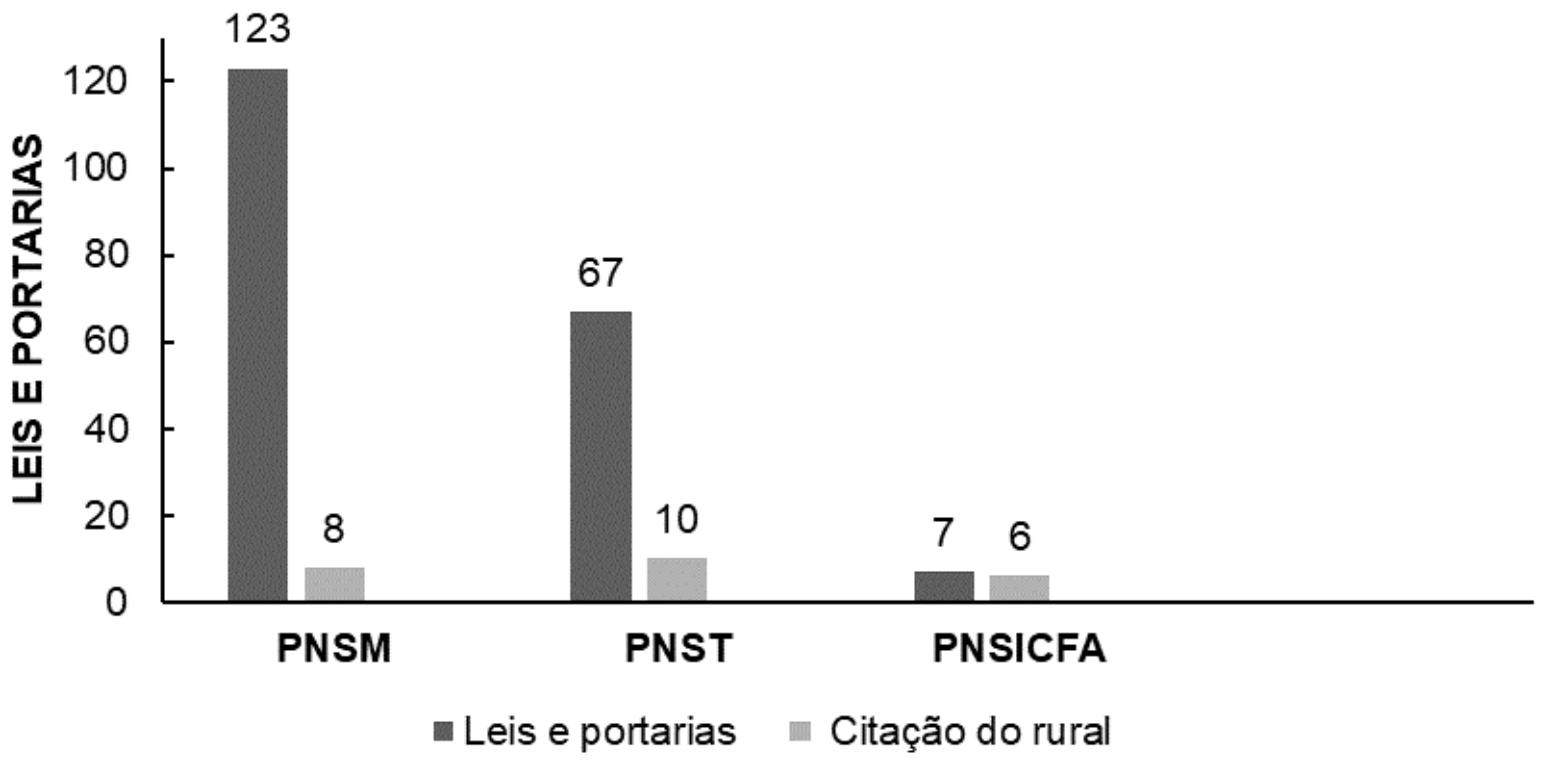

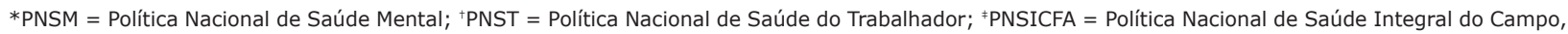
da Floresta e das Águas

Figura 1 - Comparativo do total de leis e portarias com a citação do rural nas Políticas Nacionais: de Saúde do Trabalhador, de Saúde Mental e de Saúde Integral do Campo, da Floresta e das Águas, no período de 1990 a 2018. Brasil, 2019

Com relação à Política de Saúde Mental, de 123 leis e portarias apenas 8 fazem referência direta ao rural. A análise qualitativa dos termos demonstra a ausência, fragmentação, superficialidade e falta de coerência conceitual da forma que é apreciado. Seu conceito dilui-se em termos como: a) "Entidades" (Confederação Nacional dos Trabalhadores na Agricultura); b) crianças com deficiência ou em "situações específicas e de vulnerabilidade": (...) do campo; c) "usuários que não têm contato com o sistema de saúde, por meio de trabalho de campo"; d) "populações vulneráveis, como: trabalhadores rurais expostos a determinados agentes tóxicos e/ou com precárias condições de vida"; e) uso de álcool dirigido à "população dos assentamentos", e f) "residentes em assentamentos da reforma agrária".

Com relação à Política de Saúde do Trabalhador, os dados estão aparentemente mais organizados numa plataforma on-line e apresentam 67 itens. Desses, apenas
10 fazem menção ao trabalhador rural. Essas referências, na maioria das citações, marcam somente a diferença do urbano e mantém a falta de definição, como por exemplo: "para trabalhadores rurais e urbanos".

Somente com a Política de Saúde Integral das Populações do Campo, da Floresta e das Águas (instituída pela Portaria $n^{\circ} 2.866$, de 2 de dezembro de 2011) é que o rural ganha notoriedade. $\mathrm{Na}$ análise dos 7 itens encontrados, 5 tratam do trabalhador rural. Porém, a abordagem não dá redirecionamento nas ações de assistência à saúde nem debatem a integração do campo nos serviços de saúde mental. O trabalhador rural é citado apenas como solicitação de representatividade social.

A segunda etapa de coleta de dados integra os dados anteriores, comparando o número de referência ao rural com o número de referência a saúde mental nas legislações e portarias das políticas nacionais pesquisadas (Figura 2). 


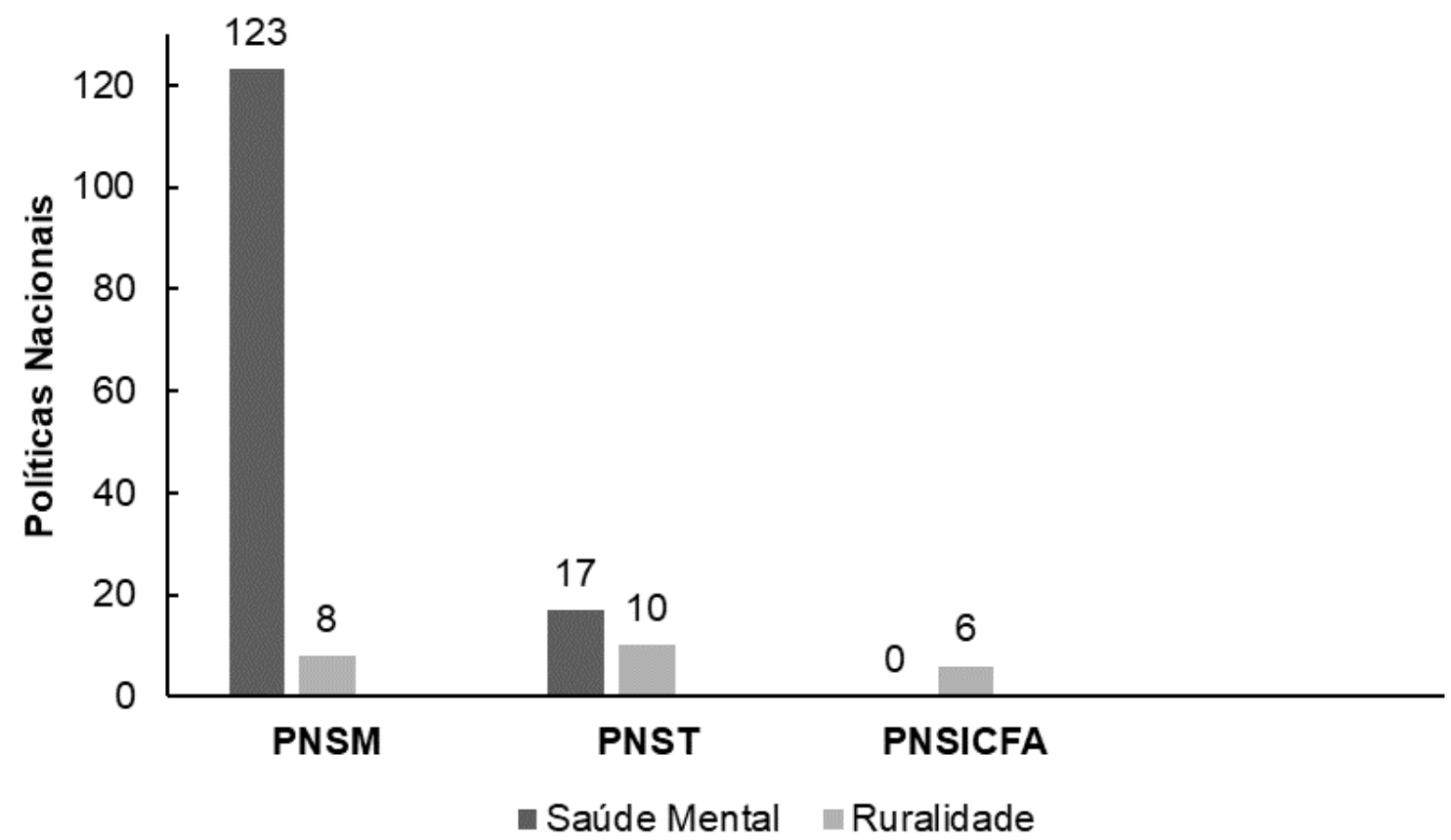

*PNSM = Política Nacional de Saúde Mental; ${ }^{+}$PNST = Política Nacional de Saúde do Trabalhador; ${ }^{*}$ PNSICFA = Política Nacional de Saúde Integral do Campo, da Floresta e das Águas

Figura 2 - Comparativo entre o total de citação sobre a ruralidade e a saúde mental nas Políticas Nacionais: de Saúde do Trabalhador, de Saúde Mental e de Saúde Integral do Campo, da Floresta e das Águas, no período de 1990 a 2018. Brasil, 2019

Esse levantamento de dados apresenta que na Política de Saúde Mental todos os itens contemplam o conceito de saúde mental e apenas 8 faz referência ao rural ou ruralidade. Na Política de Saúde do Trabalhador, 17 itens referem saúde mental e 10 ruralidades, sendo que em geral os termos são apenas citados de forma genérica, restrito a uma condição de saúde para admissão ao trabalho e não enquanto possibilidade de sofrimento. Na Política de Saúde Integral, não há referência à saúde mental e quase todos os itens abordam a ruralidade.

\section{Discussão}

As transformações sociais operam impactos que induzem a reelaboração constante de conceitos, principalmente no campo de identidade sociocultural. Para compreender o adoecimento no trabalhado rural é necessário, sobretudo, discutir o rural. De forma geral, ele é usado como antônimo de urbano. Essa definição recebe muitas críticas, na medida que deixa de construir características importantes para focar nas carências de forma comparativa ${ }^{(9-10)}$.

Algumas características consensuais são: a) agricultura não equivale a rural b) apresenta multissetorialidade e multifuncionalidade; c) densidade populacional baixa; d) e não é totalmente isolado dos espaços urbanos. Já trabalho rural, refere-se à atividade humana de diversidade econômica, de relação direta com a natureza fundamentada nas relações familiares ou familiarizadas. A valorização da terra é ampliada, pois a atividade é desenvolvida nela para subsistência da comunidade ${ }^{(11)}$.

É coerente que a concepção de rural seja baseada a partir da análise de território, tendo como bojo a Geografia social. Trabalhador rural deve ser compreendido a partir da concepção territorial, um lugar de construção de relações pessoais, sociais, políticas e culturais que influenciam diretamente os modos de vida e de produção dos habitantes. No Brasil, a constituição do rural traz uma marca escravagista, legalizada até 1888. Negligência assim como o Estatuto do Trabalhador Rural, que só foi criado bem depois das leis que garantiam os direitos dos empregados urbanos ${ }^{(12-13)}$.

A definição não dicotômica fundamenta uma visão ampliada. Nessa pesquisa, seguimos essa concepção de rural, incluindo as duas principais áreas da atividade agrícola do pais, a Agricultura Familiar e o Agronegócio. Um não exclui o outro e a abordagem mais universal permite compreender a interdependência e complementaridade de tais atividades. Muitas vezes, a concepção antagônica busca ideologizar a leitura numa distorção maniqueísta, que confunde ou desconhece os conceitos teóricos criando um confronto desnecessário(14).

Atualmente é possível destacar sete fatores que estão reorganizando um novo rural: a) consolidação do 
modo de produção capitalista na agricultura; b) processo migratório no sentido rural-urbano; c) princípios e técnicas ligadas ao padrão global de acumulação de capital; d) novas formas de ocupação da população; e) reordenação dos espaços geográficos relacionados a produção e consumo; f) novos temas relacionados ao mercado de trabalho rural; g) e a decisão sobre o que produzir passa a ser determinada externamente e interdependente de agentes econômicos ${ }^{(15)}$.

Se o quadro da ruralidade brasileira foi gradativamente moldado pelo Estado e condicionado às políticas públicas, o mesmo não ocorre no âmbito da saúde mental, menos ainda no que se refere à saúde mental do trabalhador rural. Somente no Governo Vargas (19301945) o olhar para o adoecimento e direito do trabalhador começa a ser institucionalizado e as políticas públicas ganham contorno. Saúde e trabalho passam a construir um valor social importante, tanto que para ser usuário da saúde pública era necessário ter um emprego(16-17).

A saúde mental ainda é um estigma e nem faz parte do vocabulário dos trabalhadores rurais. Um exemplo disso é a pesquisa realizada com agricultores familiares do município de Santo Antônio do Monte/ MG, que apurou desconhecimento geral. Na concepção desses trabalhadores, problema de saúde é equivalente a problemas físicos como "problema do coração" e saúde está vinculada à alimentação saudável do campo, diferentemente dos alimentos industrializados da cidade $^{(18)}$.

O desafio de pensar a questão do adoecimento mental do rural é enorme não só pelo estigma e desconhecimento, mas principalmente pela diversidade de características e vivência dessa população em territórios tão plurais. A questão econômica também é um fator importante, na medida em que aproximadamente $50 \%$ da população rural vive em condição precária. Mesmo que os dados venham mostrando a diminuição dessa desigualdade com um aumento significativo de renda, ainda há precarização do trabalho(19-20).

Com relação à análise das políticas públicas, é possível afirmar que o direito de uma determinada população não está garantido simplesmente por ser citada na legislação. Contudo, a frequência e a forma como uma determinada população é referida na implementação de normativas importantes pressupõem uma relevância conceitual, aponta para um lugar simbólico dentro da agenda política e marca a sua relação com o Estado.

Se por um lado, há um reconhecimento de que essa população apresenta vulnerabilidade e não se equipara ao urbano, por outro, a abordagem se encerra nessa premissa. O avanço das Políticas de saúde em termos de desinstitucionalização e implementação de serviços extra hospitalares, de base comunitária, são claramente considerados na proposta. Porém, não há especificidade do trabalhador rural e os serviços são propostos numa visão generalista e urbanizada.

A reforma psiquiátrica possibilitou um olhar diferenciado sobre o sofrimento psíquico, trazendo dignidade ao sujeito que sofre. Entretanto, uma das críticas contundentes é de que ainda carece principalmente de ações integradas, formação de recursos humanos, insuficiência de profissionais e políticas sociais. Tais aspectos respingam diretamente na área rural que apresenta mais dificuldade de acesso e compreensão dos processos da RAPS(19-21).

A desarticulação entre o trabalhador rural e a política de saúde mental fica mais evidente nessa análise. Mesmo com a criação da Rede Nacional de Atenção Integral à Saúde do Trabalhador e dos Centros de Referências de Saúde do Trabalhador, a saúde mental é só mais um item dentre tantos que pode ter nexo causal com o trabalho. Sobretudo, o que mais chama atenção é a dificuldade na própria legislação em definir essa causalidade, abordando o termo transtorno mental relacionado ao trabalho de forma genérica e de difícil definição.

Se não há uma definição por parte dos legisladores sobre a população rural, nem sobre o trabalhador rural e a relação entre adoecimento mental e trabalho não é clara, muito menos prioridade, como é possível esperar efetividade de políticas públicas nesse âmbito? A ineficiência da presença do Estado fica posta desde a concepção da sua marca fundamental, Estado como garantidor de direitos. O lastro simbólico e a precariedade da abordagem ficam incompletos e evidentes.

Uma das primeiras atividades a ser desenvolvida pela Atenção Primária em Saúde seria o diagnóstico da situação de saúde do território, incluindo mapeamento das atividades produtivas, identificação das situações de vulnerabilidade e possíveis impactos, riscos e perigos para a saúde dos trabalhadores. Na questão rural, esses objetivos são extremamente prejudicados, encontrando barreiras como: áreas mais remotas, baixa densidade demográfica, populações pequenas dispersas em vasto território, longa distância dos centros urbanos e trajetos com condições precárias(22-23).

Os avanços com relação à implementação da atenção ao bem-estar do trabalhador no sistema de saúde não debelam as críticas, principalmente quanto à falta de articulação com a rede, setorialização, falta de subsídios operacionais que contribuam para que a Rede Nacional de Atenção Integral à Saúde do Trabalhador possa desempenhar seus objetivos. Além disso, falta planejamento e capacidade de resposta das equipes nos diversos níveis de atuação dos Centros de Referências de Saúde do Trabalhador(24).

Na Política Nacional mais atual, que propõe integração e atenção a comunidades mais isoladas, é possível observar uma mudança de conceito que nas políticas 
anteriores abordam "trabalhador rural" ser modificado para "trabalhador do campo", sem nenhum contorno de conjuntura teórica. Essa ampliação do termo inclui o máximo de usuários em atividade no campo, inclusive na convocação de vários atores para a sua formulação. A análise dos dados conserva a dificuldade de compreender o lugar do trabalhador rural portador de sofrimento ou transtorno mental dentro do sistema de saúde.

A Política de Saúde Integral amplia a discussão sobre a saúde do trabalhador rural, e marca um posicionamento positivo do Estado quanto à alteração dessa demanda. Porém, ainda não se consolida como marco regulador dos serviços de saúde, é pouco conhecida e não conseguiu implementar nenhuma ação articulada, significativa e com eficiência que provoque mobilizações e resultados territoriais. E principalmente, não contempla o tema da saúde mental do trabalhador rural.

De modo geral, a pesquisa corrobora que historicamente a zona rural tem pouca atuação governamental, principalmente no que se refere à promoção da saúde e assistência social. Essa carência é anunciada em todos os níveis da federação, com falta de atuação e atenção aos cuidados de saúde, com grande negligência ao campo da saúde mental a nível nacional(25).

Nesse sentido, mesmo com todos os avanços e mudanças paradigmáticas da atenção psicossocial, bem como das políticas públicas em saúde, a ausência histórica da saúde mental voltada a esses trabalhadores é clara na construção desse percurso. Algumas hipóteses podem estar relacionadas à dificuldade geográfica, aos estigmas e ao despreparo das equipes. Além de ter que se deslocar e se organizar de forma muito mais exaustiva, o trabalhador com sofrimento e adoecimento psíquico não tem encontrado acolhimento e se depara com a não escuta do seu modo de vida(26).

Positivamente, se articularmos a evolução das portarias que apontam o processo da reforma psiquiátrica, implementação e financiamento de novos modelos de atenção da saúde mental, com as deliberações orçamentárias e efetivação de serviços vinculados à saúde do trabalhador é possível constatar avanços importantes, acolhimento das demandas de saúde mental e saúde do trabalhador na rede de atenção básica por meio de políticas públicas instrumentalizadas, com marcos regulatórios e participação de atores de diferentes arenas.

Negativamente, as demandas do rural ainda padecem nesse processo. Não há integralidade dos temas, mesmo com a proposta de uma Política que priorize essa parte da população. Essa ausência é preocupante e pode representar: a) dificuldade de relação entre nexo causal de saúde mental e trabalho; b) desconhecimento da correlação na saúde integral; c) falta de articulação e diálogo intersetorial; d) falta de estudos epidemiológicos e registro referente ao diagnóstico de transtorno mental que corrobore a importância dessa inserção; e) ausência de dados e estudos sobre acesso da área rural às políticas públicas de saúde mental; f) falta de profissionais, capacitação e instrumentalização; g) preconceito e desinteresse pelas demandas do campo.

Com relação à saúde mental dessa população o quadro agrava-se, na medida em que a credibilidade da discussão não consegue acompanhar a elaboração da legislação. Da mesma forma, não há coerência no campo conceitual da abordagem feita pelo Estado, nem atuação de políticas específicas. Ou seja, a falta de dados na criação das políticas públicas corrobora para a invisibilidade do debate e não revela a gravidade do assunto.

Em suma, quando se fala em saúde mental se ignora o rural, quando se fala em trabalhador rural a saúde mental é citada de forma rasa e sem definição específica ou discussão de acesso aos serviços de saúde da rede básica. Constata-se, portanto, que a saúde mental do trabalhador rural não entra como prioridade e não é incorporada com robustez nas agendas das políticas nacionais.

\section{Conclusão}

Este artigo procura contribuir para o fomento da discussão desse tema praticamente ignorado, as políticas públicas de saúde mental do trabalhador rural. É possível constatar a sua invisibilidade perante o Estado, a precariedade de princípios fundamentais aos cuidados de saúde dessa população, ausência de marcos regulatórios e a falha conspícua no que tange à construção das diretrizes das políticas nacionais de saúde para o rural.

Com base no apresentado é possível afirmar que saúde mental, trabalhador e rural formam campos distintos na construção das políticas de saúde, confusos quanto a sua articulação e deslocados enquanto demanda de serviço. O detalhamento sócio-histórico da construção dessas políticas confirma que essa demanda aparece fragmentada, ambígua e sem conceito definido, no desenho dos instrumentos da rede de atenção e tratadas superficialmente dentro de paradigmas generalizantes, nem um pouco territorializadas, articuladas e integrativas.

Portanto, urge a necessidade de: a) avançar nas pesquisas sobre o tema para gerar resposta, buscando construir uma consciência coletiva sobre a necessidade de enfrentamento desse problema; b) inferir a importância de avaliar e monitorar a saúde e o sofrimento mental das comunidades rurais em que esse trabalhador está inserido; c) considerar e avaliar o acesso aos serviços dessa população e o desenvolvimento de tratamentos eficazes com monitoramento e avaliação das ações de saúde mental, repensando o lugar de acolhimento dessa demanda; d) capacitar os profissionais especialmente da 
rede de atenção básica e em cuidados primários que de forma clara incluam o trabalhador rural.

Cabe aos atores sociais envolvidos com o tema impulsionar a discussão nas diferentes arenas e responsabilizar os gestores a fim de assegurar a elaboração e implementação de políticas de saúde mental amplas, descentralizadas e territorializadas, fundamentalmente pelo empenho na construção de dados epidemiológicos, avaliação de demandas e integração do tratamento e dos serviços de saúde mental no sistema geral de saúde vigente.

\section{Referências}

1. Grisa C, Schneider S, organizadores. Políticas públicas de desenvolvimento rural no Brasil. Porto Alegre: Editora da UFRGS; 2015. 624 p.

2. Miranda $C$, organizador. Tipologia regionalizada dos espaços rurais brasileiros: implicações no marco jurídico e nas políticas públicas. Brasília: IICA; 2017. 484 p.

3. Ministério da Saúde (BR). Secretaria de Gestão Estratégica e Participativa. Departamento de Apoio à Gestão Participativa. Relatório do II Encontro Nacional de Saúde das Populações do Campo e da Floresta. Brasília: Ministério da Saúde; 2014.

4. Ministério da Saúde (BR). Secretaria de Atenção à Saúde. Secretaria de Vigilância em Saúde. Saúde do Trabalhador e da Trabalhadora. Cadernos de Atenção Básica, n. 41. Brasília: Ministério da Saúde; 2018.

5. Miranda C, Silva H, organizadores. Concepções de ruralidade contemporânea: as singularidades brasileiras. Série Desenvolvimento Rural Sustentável, v. 21. Brasília; 2013. 476 p.

6. World Health Organization. Depression and other common mental disorders: global health estimates. [Internet]. Geneva: WHO; 2017 [cited 2019 Mar 1]: Available from: https://apps.who.int/iris/bitstream/ handle/10665/254610/WHO-MSD-MER-2017.2-eng. pdf?sequence $=1$

7. Pessoa VM, Almeida MM, Carneiro FF. Como garantir o direito à saúde para as populações do campo, da floresta e das águas no Brasil? Saúde Debate. 2018;42(spe 1):30214. doi:http://doi.org/10.1590/0103-11042018s120

8. Hochman G, Arretche M, Marques E, organizadores. Políticas públicas no Brasil [Internet]. Rio de Janeiro: Editora FIOCRUZ; 2007. Disponível em: http://books. scielo.org/id/kgkv6

9. Murray G, Judd F, Jackson H, Fraser C, Komiti A, Hodgins $G$, et al. Rurality and mental health: the role of accessibility. Aust N Z J Psychiatry. 2004;38(8):629-34. doi: http://doi.org/10.1080/j.1440-1614.2004.01426.x 10. Peres F. Saúde, trabalho e ambiente no meio rural brasileiro. Ciênc Saúde Coletiva. 2009;14(6):1995-2004. doi:http://doi.org/10.1590/S1413-81232009000600007
11. Santos TGD, Kahlau C, Isaguirre KR. O trabalho rural e os povos da terra no projeto rural brasileiro: há desenvolvimento no vazio das gentes? Emancipação. 2017;17(2):182-98. doi: http://doi.org/10.5212/ Emancipacao.v.17i2.0001

12. Souza HM de, Marlon GN, Souza PM, Ney VSP. Escolaridade, Carteira de Trabalho e Renda dos Empregados no Meio Rural Brasileiro. [Internet]. Campo - território: Rev Geografia Agrária. 2015 [Acesso 28 mar 2018];10(20):468-92. Disponível em: http://www.seer. ufu.br/index.php/campoterritorio/article/view/27044 13. Silva ES. Os vínculos entre condições de trabalho e saúde mental. Psicol Cienc Profissão. [Internet]. 1988 [Acesso 7 ago 2018];8(2);13-6. Disponível em: http://pepsic.bvsalud.org/scielo.php?script=sci_ arttext\&pid=S1414-98931988000200006\&lng=pt\&nrm $=$ iso

14. Silva A, Breitenbach R. O debate "agricultura familiar versus agronegócio": as jaulas ideológicas prendendo os conceitos. Extensão Rural. 2013;20(2):62-85.

15. Mattei LF. Sistema de proteção social brasileiro enquanto instrumento de combate à pobreza. Rev Katálysis. 2019;22(1):57-65. doi: http://doi. org/10.1590/1982-02592019v22n1p57

16. Perez KV, Bottega CG, Merlo ARC. Análise das políticas de saúde do trabalhador e saúde mental: Uma proposta de articulação. Saúde Debate. 2017;41(spe2):287-98. doi: http://doi.org/10.1590/0103-11042017s224

17. Santos FR dos, Bezerra L Neto. Políticas públicas para a educação rural no Brasil: da omissão à regulamentação do programa nacional de educação na reforma agrária. Rev HISTEDBR On-line. 2016;15(66):178-95. doi: http:// doi.org/10.20396/rho.v15i66.8643709

18. Ribeiro LP, Brant FLC, Pinheiro TMM. Saúde, trabalho e adoecimento: o trabalho como mediador das representações sociais de agricultores familiares. Rev Med Minas Gerais. 2015;25(4):493-501. doi: http://doi. org/10.5935/2238-3182.20150113

19. Costa MC Neto, Dimenstein M. Cuidado Psicossocial em Saúde Mental em Contextos Rurais. Temas Psicol. 2017;25(4):1653-64. doi: http://doi.org/10.9788/ TP2017.4-09Pt.

20. Costa MC Neto, Dimenstein M. Saúde Mental em Contextos Rurais: o Trabalho Psicossocial em Análise. Psicol Cienc Profissão. 2017;37(2):461-74. doi: http:// doi.org/10.1590/1982-3703002542016

21. Guedes AC, Kantorski LP, Pereira PM, Clasen BN, Lange C, Muniz RM. A mudança nas práticas em saúde mental e a desinstitucionalização: uma revisão integrativa. Rev Eletr Enferm. 2010;12(3):547-53. doi: http://doi.org/10.5216/ ree.v12i3.8198

22. Fausto MCR, Fonseca HMS da, Goulart VMP. Atenção primária à saúde em territórios rurais e remotos no Brasil. [Internet]. (Projeto de Pesquisa). Rio de Janeiro (RJ): 
Fundação Oswaldo Cruz; 2019 [Acesso 11 mar 2019]: Disponível em: https://cee.fiocruz.br/sites/default/files/ ProjetoAPSruraleremotomodificado2019.pdf

23. Gómez CM. Avanços e entraves na implementação da Política Nacional de Saúde do Trabalhador. Rev Bras Saúde Ocup. 2013;38(127):11-30. doi: http://doi.org/10.1590/ S0303-76572013000100004

24. Silva VHF, Dimenstein M, Leite JF. O cuidado em saúde mental em zonas rurais. Mental. 2012;10 (19):267-85. 25. Dantas CMB, Dimenstein M, Leite JF, Torquato J, Macedo JP. A pesquisa em contextos rurais: desafios éticos e metodológicos para a psicologia. Psicol Soc. 2018;30:e165477. doi: http://doi. org/10.1590/1807-0310/2018v30165477

26. Ruiz ENF, Santos VF dos, Gerhardt TE. Mediações na atenção à saúde sob a ótica da Teoria da Dádiva: a saúde da população rural em destaque. Physis. 2016;26 (3):829-52. doi: http://doi.org/10.1590/ s0103-73312016000300007

\section{Contribuição dos autores}

Concepção e desenho da pesquisa: Raimundo Nonato Cunha de França, Cláudia Farias Pezzini. Obtenção de dados: Cláudia Farias Pezzini. Análise e interpretação dos dados: Cláudia Farias Pezzini. Redação do manuscrito: Cláudia Farias Pezzini. Revisão crítica do manuscrito quanto ao conteúdo intelectual importante: Raimundo Nonato Cunha de França.

Todos os autores aprovaram a versão final do texto.

Conflito de interesse: os autores declararam que não há conflito de interesse.
Copyright ( 2021 SMAD, Rev Eletrônica Saúde Mental Álcool Drog. Este é um artigo de acesso aberto distribuído sob os termos da Licença Creative Commons CC BY.

Esta licença permite que outros distribuam, remixem, adaptem e criem a partir do seu trabalho, mesmo para fins comerciais, desde que the atribuam o devido crédito pela criação original. É a licença mais flexível de todas as licenças disponíveis. É recomendada para maximizar a disseminação e uso dos materiais licenciados. 